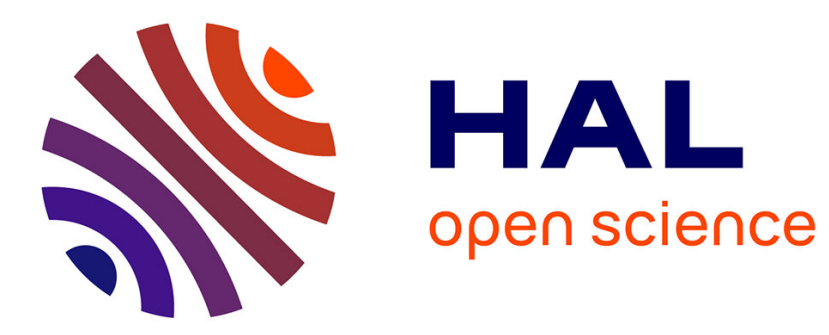

\title{
Direct modeling of material deposit and identification of energy transfer in gas metal arc welding
}

Michel Bellet, Makhlouf Hamide

\section{To cite this version:}

Michel Bellet, Makhlouf Hamide. Direct modeling of material deposit and identification of energy transfer in gas metal arc welding. International Journal of Numerical Methods for Heat and Fluid Flow, 2013, 23 (8), pp.1340-1355. 10.1108/HFF-01-2012-0018 . hal-00923628

HAL Id: hal-00923628

https: / hal-mines-paristech.archives-ouvertes.fr/hal-00923628

Submitted on 25 Apr 2014

HAL is a multi-disciplinary open access archive for the deposit and dissemination of scientific research documents, whether they are published or not. The documents may come from teaching and research institutions in France or abroad, or from public or private research centers.
L'archive ouverte pluridisciplinaire HAL, est destinée au dépôt et à la diffusion de documents scientifiques de niveau recherche, publiés ou non, émanant des établissements d'enseignement et de recherche français ou étrangers, des laboratoires publics ou privés. 


\title{
Direct Modeling of Material Deposit and Identification of Energy Transfer in Gas Metal Arc Welding
}

\author{
Michel Bellet, Makhlouf Hamide \\ MINES ParisTech, CEMEF - Centre de Mise en Forme des Matériaux \\ CNRS UMR 7635, Sophia Antipolis, France \\ michel.bellet@mines-paristech.fr
}

\begin{abstract}
Purpose - The purpose of this paper is to present original methods related to the modeling of material deposit and associated heat sources for finite element simulation of gas metal arc welding (GMAW).

Design/methodology/approach - The filler deposition results from high frequency impingements of melted droplets. The present modeling approach consists of a time-averaged source term in the mass equation for selected finite elements in the fusion zone. The associated expansion of the mesh is controlled by means of adaptive remeshing. The heat input includes a volume source corresponding to the droplets energy, for which a model from the literature is expressed in coherency with mass supply. Finally, an inverse technique has been developed to identify different model parameters. The objective function includes the differences between calculations and experiments in terms of temperature, but also shape of the fusion zone.

Findings - The proposed approach for the modeling of metal deposition results in a direct calculation of the formation of the weld bead, without any a priori definition of its shape. Application is shown on GMAW of steel $316 \mathrm{LN}$, for which parameters of the model have been identified by the inverse method. They are in agreement with literature and simulation results are found quite close to experimental measurements.

Originality/value - The proposed algorithm for material deposit offers an alternative to the element activation techniques that are commonly used to simulate the deposition of filler metal. The proposed inverse method for parameter identification is original in that it encompasses an efficient and convenient technique to take into account the shape of the fusion zone.
\end{abstract}

Keywords Welding, Fusion zone, Metal deposition, Heat source, Finite element, Inverse method.

Paper type Research paper 


\section{Introduction}

In the literature, there are two main approaches in numerical modeling of welding. A first class of models focuses on heat and fluid flow: "HFF" models address the physical phenomena occurring in the fusion zone: buoyancy, capillary and electromagnetic effects (Kim et al., 2003; Cao et al., 2004; Hu et al., 2008). A second class of models - named "TMM" for Thermo-Mechanics and Metallurgy - aims at calculating stresses, strains and microstructural evolutions in assembled parts. They address the coupled heat transfer, metallurgical transformations and mechanical phenomena occurring in the neighborhood of the weld pool, but also at larger scales in welded parts. In such models, the actual physics taking place in the fusion zone is replaced by simplified models. The melted material is considered as a viscoplastic or Newtonian fluid of arbitrary high viscosity, thus ignoring complex fluid flow. In addition, in order to mimic the convective heat transfer occurring in the fusion zone, different methods are used: augmented or anisotropic heat conductivity, additional volume heat source (Goldak, 1986). TMM approaches are widely used see the three-part review of Lindgren (2001) and (Lindgren, 2006) - but they suffer from a specific limitation regarding the modeling of weld bead formation in the context of gas metal arc welding (GMAW). During GMAW, material deposit results from droplets of melted filler material, falling into the weld pool and forming the joint after solidification. In TMM models, this metal supply is generally modeled by progressive activation of the finite elements that constitute the weld bead, according to the electrode displacement (Lindgren et al., 1999). This approach has three major limitations:

- The geometry of the weld bead is defined a priori;

- The construction of the mesh is painful and time consuming;

- This generally impedes dynamic remeshing.

In the present TMM approach, metal deposition and joint formation are modeled in a more physical way with fewer constraints. The basic idea consists in implementing a source term in the mass equation for some selected elements of the fusion zone. Consistently, a corresponding source term is considered in the energy equation. The paper is organized as follows. Section 1 presents the main features of the TMM method. Section 2 addresses the modeling of material deposit and associated energy transfer. In Section 3, an application is given, including parameter identification by an original inverse finite element method.

\section{Thermomechanical Modeling of Arc Welding Processes}

The authors have developed a TMM three-dimensional finite element model for arc welding, named TRANSWELD (Pequet et al., 2006; Hamide and Bellet, 2007; Hamide, 2008; Hamide et al., 2008). It is based on coupled solutions of heat transfer, metallurgical kinetics and mechanics. Because the present paper focuses on material and energy deposit, the presentation is limited here to the main features of the thermomechanical resolution, which is based upon the approach proposed by Bellet and Fachinotti (2004) and Bellet et al. (2005). See details in references.

- Energy conservation is solved using an enthalpy-based formulation. Each element (tetrahedron) is considered either solid-like or fluid-like, depending on temperature: over the solidus temperature $T_{S}$, the element is considered liquid-like, below it is solid-like.

- A thermo-viscoplastic (TVP) model is used in liquid-like elements (mushy or liquid state) The model is of power-law type and encompasses the Newtonian behavior in liquid state. A thermo-elastic-viscoplastic (TEVP) model is used in solid-like elements. 
- Momentum and mass conservation equations are solved concurrently in a mixed velocitypressure formulation. The solution provides the material velocity in solid and melted regions, together with stress and strains in solid regions.

- The incremental updating of nodal positions is performed through an arbitrary Lagrangian-Eulerian technique (ALE). Solid nodes are updated using the calculated material velocity. Other nodes are updated by a barycentering method in order to preserve a good element aspect ratio.

- The mesh boundary represents the material surface. An anisotropic remeshing procedure is used from time to time, based upon an error estimator (Hamide et al., 2008).

- At each time increment, the resolution is divided in 4 modules. Step 1: thermal resolution, providing temperature and liquid metal fraction. Step 2: mechanical resolution, providing velocity and pressure fields, and the stress tensor in solid-like elements. Step 3: mesh updating using ALE scheme. Step 4: possible adaptive remeshing.

\section{Modeling of Material Deposit}

During GMAW, the material deposit results from droplets of melted filler material, arising from the fusion of the consumable electrode. These droplets fall down into the weld pool after they have been accelerated during their flight through the electric arc plasma. The progressive and continuous solidification of the weld pool gives birth to the weld joint. In the next paragraphs, we will give the expressions of the mass input and associated energy input to the fusion zone, corresponding to the impingement of droplets. We will then deduce the appropriate source terms to be considered in the mass and energy equations.

\subsection{Modeling of Mass Transfer}

\subsubsection{Mass flow rate and droplets impingement zone}

In GMAW context, the mass flow rate is simply $\dot{m}_{w}=\rho_{w} \pi R_{w}{ }^{2} v_{w}$, where $R_{w}$ and $v_{w}$ are respectively the radius and velocity of the filler wire, $\rho_{w}$ its density at initial temperature $T_{0, w}$. Assuming there is no material loss through the arc plasma, $\dot{m}_{w}$ represents the time-averaged mass flow rate associated with the high-frequency impingement of metal droplets in the fusion zone. Thus, locally in the fusion zone, this time-averaged material supply can be modeled by a source term in the mass conservation equation. A first task consists in selecting elements of the fusion zone that would be affected by such a source term. For this purpose, a virtual cone may be attached to the electrode tip (Figure 1). Selected elements are those in the liquid state and located inside the cone: elements colored in red. However, accelerated melted metal droplets penetrate deeply into the bath. This phenomenon is responsible, together with Marangoni effect, for the characteristic finger-type shape of the weld pool (see Figure 4 in Section 3 for instance). Therefore, rather than a cone, we consider the model suggested by Kumar and Badhuri (1994), after Lancaster (1986). These authors suppose that each droplet impingement generates a cylindrical cavity. Its radius, $R_{\text {fill }}$, is supposed twice as big as the droplet radius, while its height, $H_{\text {fill }}$, can be determined by an energy balance commented hereafter. $R_{\text {fill }}$ is obtained from wire radius and velocity, and the detachment frequency of the droplets, $f_{d}$, using mass conservation:

$$
R_{\text {fill }}=2 R_{\text {drops } f_{-}}=2\left(\frac{3}{4 f_{d}} \frac{\rho_{w}}{\rho_{w}\left(T_{d r o p s_{-} f}\right)} R_{w}{ }^{2} v_{w}\right)^{\frac{1}{3}}
$$


$f_{d}$ depends on the shielding gas and welding intensity. Rhee and Kannatey-Asibu (1992) have shown that the transition from globular to spray-type transfer occurs around $300 \mathrm{~A}$. Their results have been exploited by Kim et al. (2003) who proposed the following sigmoid function:

$$
f_{d}=\frac{-243.44}{1+\exp \left(\frac{I-291.086}{6.06437}\right)}+323.506-0.874 I+0.0025 I^{2}
$$

Hence $R_{\text {fill }}$ can be fully determined knowing $I, R_{w}, v_{w}, \rho_{w}$. Regarding now $H_{\text {fill }}$, it is determined by the model of Kumar and Badhuri (1994) which consists in assuming that the energy needed to form such a cavity, that is the work of hydrostatic pressure and liquid surface tension along the cavity wall, is provided by the droplet kinetic energy:

$$
H_{\text {fill }}=-\frac{\gamma}{R_{\text {drops } f_{-}} \rho g}+\sqrt{\left(\frac{\gamma}{R_{\text {drops }_{-}} \rho g}\right)^{2}+\frac{R_{\text {drops } f_{-} v_{\text {drops } f}{ }^{2}}}{3 g}}
$$

where $g$ denotes gravity, $\rho$ the density, $\gamma$ the surface tension, and $v_{\text {drops } f}$ the impinging velocity. $v_{\text {drops } f}$ can in turn be expressed as a function of material and welding parameters. Assuming a constant acceleration, we get:

$$
v_{\text {drops_f }}=\sqrt{v_{\text {drops_d }}^{2}+2 a_{\text {drops }} L_{\text {arc }}}
$$

where $v_{\text {drops } \_} d$ is the initial detachment velocity, $L_{a r c}$ the arc length and $a_{\text {drops }}$ the acceleration, which can be estimated from the second law of Newton. However, as noted by Jones et al. (1998), it seems preferable to deduce $a_{\text {drops }}$ or $v_{\text {drops_f }}$ directly from experiments.

\subsubsection{Source term in mass equation}

In selected elements, a mass source term is considered. Assuming a uniform distribution of the mass supply, we get:

$$
\frac{\partial \rho}{\partial t}+\nabla \cdot(\rho \mathbf{v})=\rho \dot{\theta}_{\text {drops }}=\frac{\dot{m}_{w}}{\sum_{K} V^{K}}
$$

where $\mathbf{v}$ denotes the velocity field, $\rho$ the density and $V^{K}$ the volume of each selected element $K$. In a non steady-state simulation, the volume integration of these expansion terms $\dot{\theta}_{\text {drops }}$ induces an evolution of the surface of the weld pool, which gives birth after solidification to the joint shape. In the ALE context, this directly affects the surface of the mesh. This is controlled by dynamic remeshing to preserve acceptable geometrical properties for the mesh.

\subsection{Modeling of Energy Transfer}

\subsubsection{Global balance}

The total welding power is the voltage-intensity product UI. It is supposed that a fraction $\eta$ is effectively used for the process. This effective power can be separated in two parts. A first part, $\dot{W}_{\text {wfus }}$, is used to melt the consumable electrode. A second part, $\dot{W}_{\text {surf }}$, corresponds to the thermal power transferred by the arc plasma to the surface of the welded material. This decomposition is characterized by the parameter $\eta_{w f u s}$ : 


$$
\begin{aligned}
U I \eta & =\dot{W}_{\text {wfus }}+\dot{W}_{\text {surf }} \\
& =\eta_{\text {wfus }} U I \eta+\left(1-\eta_{\text {wfus }}\right) U I \eta
\end{aligned}
$$

The filler is heated from its initial temperature $T_{0, w}$ to the temperature of the droplets when they detach: $T_{\text {drops } \_d}$. Assuming a constant specific heat $c_{p, w}$, we have:

$$
\dot{W}_{w f u s}=\dot{m}_{w}\left(c_{p, w}\left(T_{d r o p s_{-} d}-T_{0, w}\right)+L_{w}\right)
$$

where $L_{w}$ is the latent heat of the wire material. Note that the combination of equations (6) and (7) provides a direct relation between the value of $\eta_{\text {wfus }}$ and $T_{\text {drops } d}$.

\subsubsection{Source term in energy equation}

The time-averaged input power to the fusion zone corresponding to impinging droplets has now to be expressed. Let us start from the equation for energy conservation:

$$
\frac{\partial(\rho h)}{\partial t}+\nabla \cdot(\rho h \mathbf{v})-\nabla \cdot(k \nabla T)=0
$$

where $h$ is the specific enthalpy and $k$ the thermal conductivity. Here, source terms associated with plastic deformation and Joule effect are ignored. In the selected elements $K$, this equation must be modified.

- First the volumetric expansion due to droplets impingement must be taken into account through equation (5).

- Second, we must consider an energy source term expressing the energy input. The specific enthalpy of droplets when entering the pool being $h_{d r o p s}=c_{p, w} T_{d r o p s_{-} f}+L_{w}$, and assuming a uniform input in selected elements, the heat source term is:

$$
\dot{w}_{d r o p s}=\frac{\dot{m}_{w}\left(c_{p, w} T_{d r o p s_{-} f}+L_{w}\right)}{\sum_{K} V^{K}}=\rho \dot{\theta}_{d r o p s}\left(c_{p, w} T_{d r o p s_{-} f}+L_{w}\right)
$$

Finally, equation (8) becomes:

$$
\rho\left(\frac{\partial h}{\partial t}+\nabla h \cdot \mathbf{v}\right)-\nabla \cdot(k \nabla T)=\dot{w}_{d r o p s}-\rho h \dot{\theta}_{d r o p s}
$$

Hence, it should be noticed that the effective energy source term does not derive directly from the distribution of the energy transported by the impinging droplets. It also includes a corrective term arising from the presence of the mass source term in the mass equation: the effective power source takes into account the volumetric expansion.

\section{Application and Validation}

\subsection{GMAW instrumented experiment}

The objective of this section is to show that the models described above for material and energy transfer can be validated by comparison with experimental measurements. The case studied here 
is a "bead-on-plate" test, consisting of a linear single-pass deposit on a plate using a GMA welding process. The base material is the austenitic stainless steel ANSI 316LN. Figure 2 shows an instrumented plate after welding. Figure 3 provides a sketch of the instrumentation. The experiment has been extensively described in the Ph.D. manuscript of Hamide (2008) and in (Aarbogh et al., 2010). The test has been originally designed for validation of thermomechanical simulations of welding and was chosen large enough to obtain a thermal quasi-stationary situation. Here, we focus on material deposit during welding. Mechanical aspects are ignored: the displacement of the plate during and after welding, the formation of strains and stresses are fully presented and discussed in the references just mentioned. The main characteristics of this experiment are the followings:

- Thick plate, $10.5 \mathrm{~mm}$ thick, $136 \mathrm{~mm}$ wide and $250 \mathrm{~mm}$ long (in the welding direction).

- A single pass metal deposit, by GMA welding technique. The electrode is maintained in a vertical position (perpendicular to the upper wide face of the plate). Its total displacement is $230 \mathrm{~mm}$, beginning and finishing at $10 \mathrm{~mm}$ from the plate border.

- The arc length $L_{\text {arc }}$ (distance between electrode and plate) is maintained constant during welding: $L_{\text {arc }}=10 \mathrm{~mm}$.

- The filler wire material is a 316LSI steel of radius $R_{w}=0.6 \mathrm{~mm}$, feed speed $v_{w}=0.2 \mathrm{~m} / \mathrm{s}$.

- The initial temperature of the plate and of the filler wire is approximately $20^{\circ} \mathrm{C}$.

- The process parameters are: welding voltage $U=29 \mathrm{~V}$, average welding intensity (controlled automatically) $U=360$ A, welding speed $v_{\text {weld }}=10 \mathrm{~mm} / \mathrm{s}$. This yields a nominal welding energy of $1.044 \mathrm{~kJ} / \mathrm{mm}$, a welding duration of $23 \mathrm{~s}$.

- The shield gas is M12 (or Arcal 12) argon (Ar) with 1 to $5 \% \mathrm{CO}_{2}$.

- The plate is equipped with twelve K-type thermocouples (chromel-alumel, $\mathrm{MgO}$ insulated with steel cap) of diameter $1 \mathrm{~mm}$, forced in pre-drilled holes, at locations indicated in Figure 3.

\subsection{Experimental Results}

Macrographies of the fusion zone are shown in Figure 4. Issued from three tests performed in the same conditions, and from two transverse sections in the plate, they show a stable and reproducible weld pool shape. The shape is characteristic of steel GMAW with a marked fingertype central penetration. The average experimental values for the width, height and depth of the fusion zone can be found in Table 2 .

Some temperature measurements by thermocouples (TCs) are reported in Figure 5, see full results in (Aarbogh et al., 2010). These results prove the stationarity of the welding, but also show a certain dispersion, with temperature differences as high as $120^{\circ} \mathrm{C}$ for $\mathrm{TCs}$ at the same nominal distance from the welding line. This can be explained by the effective position of TCs, which can be measured a posteriori. Indeed, significant positioning errors have been recorded, up to $1.5 \mathrm{~mm}$ for TC2 in test 2 . It can be thought that different contact conditions in drilled holes may also contribute to the observed scattering.

\subsection{Modeling Hypotheses and Parameters}

The parameters of the different models used in the direct simulation and in the identification procedure for parameter identification are as follows.

- Convection with air and gray-body radiation are assumed on all faces of the plate, with following parameters: heat transfer coefficient $h_{\text {conv }}=5 \mathrm{~W} \mathrm{~m}^{-2} \mathrm{~K}^{-1}$, thermal emissivity $\varepsilon_{\text {rad }}=0.25$, air temperature $T_{\text {air }}=20^{\circ} \mathrm{C}$.

- The temperature of droplets is supposed to be unchanged during their flight: $T_{\text {drops_f }}=T_{\text {drops_d }}$. 
- The arc heating power $\dot{W}_{\text {surf }}$ transferred to the surface of the plate is modeled by a Gaussian surface heat source inside a cone of characteristic angle $2 \alpha$, as illustrated in Figure 6 . The corresponding surface heat flux is defined by

$$
\phi(d, r)=\frac{3 \dot{W}_{\text {surf }}}{\pi(d \tan \alpha)^{2}} \exp \left(-\frac{3 r^{2}}{(d \tan \alpha)^{2}}\right)
$$

In this expression, $r$ stands for the radial distance of the studied point at the surface of the metal to the axis of the electrode and $d$ stands for the distance to the electrode along its axial direction ( $d$ is then quite close to the arc length $L_{\text {arc }}$ ).

- The droplet impingement zone is cylindrical, as described in Section 2.1.1. Its dimensions are fixed to $R_{\text {fill }}=1.0 \mathrm{~mm}$ and $H_{\text {fill }}=2.0 \mathrm{~mm}$, according to the following analysis.

$\circ$ The radius $R_{\text {fill }}$ is determined by equation (1), using an estimation of the droplets detachment frequency provided by equation (2). The density of the wire metal is taken constant: $\rho_{w}=7400 \mathrm{~kg} \mathrm{~m}^{-3}$. Using the experimental data of Section 3.1, the following values are obtained: $f_{d}=333 \mathrm{~Hz}, R_{\text {drops } f}=0.55 \mathrm{~mm}, R_{\text {fill }}=1.09 \mathrm{~mm}$.

○ The height $H_{\text {fill }}$ is determined by equation (3), using the following parameters. The surface tension is taken as $\gamma=1 \mathrm{~N} \mathrm{~m}^{-1}$. The impingement velocity of droplets is estimated by equation (4) in which the detachment velocity is extrapolated from the experimental results obtained by Jones et al. (1998): $v_{\text {drops_d }}=1.2 \mathrm{~m} \mathrm{~s}^{-1}$, and the acceleration is assumed constant during transfer and taken from the work of Kim et al. (2003) as: $a_{\text {drops }}=200 \mathrm{~m} \mathrm{~s}^{-2}$. This yields an estimation of the impingement velocity: $v_{\text {drops }_{-} f}=2.3 \mathrm{~m} \mathrm{~s}^{-1}$. Applying equation (3), we obtain $H_{v h s}=1.9 \mathrm{~mm}$.

- An arbitrarily increased heat conductivity is used, defined by $k_{\text {eff }}=f_{k} k$, where $k$ is the nominal conductivity of the material and $f_{k}$ a multiplicative parameter to be identified.

- The simulation is run on a computational domain covering one half of the specimen, respecting the symmetry with respect to the welding line.

- Mesh size parameters are $h_{\min }=0.8 \mathrm{~mm}$ and $h_{\max }=7 \mathrm{~mm}$.

- The full set of material parameters of steel 316LN used for the calculations can be found in (Aarbogh et al., 2010).

\subsection{Identification of Parameters and Comparison}

Four parameters should be identified: the overall welding heat efficiency $\eta$ (fraction of power effectively transferred to the plate), the magnification factor for heat conductivity $f_{k}$, the semiangle of the Gaussian heat source $\alpha$, the fraction of heat power used for the fusion of the filler wire $\eta_{w f u s}$. They form the four components of vector $\mathbf{q}$.

An inverse analysis technique is used to identify q. The basic principle of the method is to adjust the values of the parameters in order to minimize the difference between numerical calculations and measurements. This difference is expressed in terms of temperatures but also of the shape of the fusion zone, as explained below. Denoting $T^{\text {exp }}$ the measured temperatures and $T^{\text {cal }}$ the calculated ones, a sampling procedure has to be defined in order that they could be compared. The calculated values $T^{\text {cal }}$ of course depend on the set of parameters $\mathbf{q}$ and on time $t$. The distance with respect to $T^{e x p}$ can be expressed in the sense of the least squares method: 


$$
\Psi(\mathbf{q})=\sum_{k=1}^{S} \sum_{i=1}^{I}\left(T_{k}^{c a l}\left(\mathbf{q}, t_{i}\right)-T_{k}^{\exp }\left(t_{i}\right)\right)^{2}
$$

where $S$ denotes the number of sensors, $k$ the sensor index, $I$ the number of sampling instants, and $i$ the index for sampling instants.

When modeling a welding process, the correct representation of the shape of the weld pool is discriminant in that it reveals the accuracy of the solution provided by the numerical model. With this in view, the function $\Psi$ is complemented with additional terms expressing that at locations where the metal is found melted in the experiment (red dots in Figure 7), the maximum of the calculated temperature should not be found below the liquidus temperature $T_{L}$. Conversely, at locations where the metal is found not melted in the experiment (blue dots in Figure 7), the maximum of the calculated temperature should not be found over the solidus temperature $T_{S}$. Two additional penalty terms $\Psi_{F Z}$ and $\Psi_{B M}$ are then expressed as follows:

$$
\Psi_{F Z}(\mathbf{q})=\sum_{k=1}^{S_{E Z}}\left\langle T_{L}-\max _{t} T_{k}^{c a l}(\mathbf{q}, t)\right\rangle^{2} \quad \Psi_{B M}(\mathbf{q})=\sum_{k=1}^{S_{B M}}\left\langle\max _{t} T_{k}^{c a l}(\mathbf{q}, t)-T_{S}\right\rangle^{2}
$$

In these expressions, $S_{F Z}$ denotes the number of selected locations in the fusion zone (red dots), and $S_{B M}$ the number of selected locations in the non-melted base metal (blue dots). The expressions between brackets reduce to zero when negative: $\langle x\rangle=(x+|x|) / 2$. Finally, the modified objective function considered in the present study has the following expression,

$$
\begin{aligned}
\tilde{\Psi}(\mathbf{q})= & \frac{\beta}{S \times I} \sum_{k=1}^{S} \sum_{i=1}^{I}\left(T_{k}^{c a l}\left(\mathbf{q}, t_{i}\right)-T_{k}^{\exp }\left(t_{i}\right)\right)^{2}+ \\
& (1-\beta)\left(\frac{1}{S_{F Z}} \sum_{k=1}^{S_{F Z}}\left\langle T_{L}-\max _{t} T_{k}^{c a l}(\mathbf{q}, t)\right\rangle^{2}+\frac{1}{S_{B M}} \sum_{k=1}^{S_{B M}}\left\langle\max _{t} T_{k}^{c a l}(\mathbf{q}, t)-T_{S}\right\rangle^{2}\right)
\end{aligned}
$$

The weighting factor $\beta$ balances temperature and pool shape contributions and is taken as 0.5 in the present work. From the three similar experimental tests presented above, test 3 is chosen as the reference for the identification. The selection of red and blue dots in the fusion zone and in the base metal, respectively, is carried out as follows. The macrographies of the two selected transverse sections of test 3 - shown in Figure 4 - can be analyzed in order to determine the profile of the fusion zone. The right and left profiles of each of the two sections (that is four profiles) are plotted in Figure 8. This allows the determination of several points in the fusion zone and in the base metal, in order to constraint the identification procedure, according to equation (14). In the present case, four points are selected in the fusion zone as well as in the base metal $\left(S_{F Z}=S_{B M}=4\right)$. The location of these points is determined arbitrarily, but it can be seen that they can be selected in order to induce an effective constraint on the solution.

The inverse problem consists then in determining $\mathbf{q}$ such that the following function $\tilde{\Psi}(\mathbf{q})$ be minimized. The minimization problem was solved using the commercial IOSO software (Egorov et al., 2005), which has been interfaced with the TRANSWELD software in charge of performing the direct simulations and of calculating the objective function. The optimization took 40 iterations (global CPU time $96 \mathrm{~h}$ on Pentium4 @ $2.8 \mathrm{GHz}$ and $1 \mathrm{~Gb}$ RAM), yielding the parameter values indicated in Table 1. These parameters are in agreement with values found in the literature (Kumar and DebRoy, 2004), except to a certain extent for the magnification 
parameter for the heat conductivity, $f_{k}$, which is found higher than standard values, typically found in the range 5 to 15 .

\begin{tabular}{|c|c|c|c|}
\hline$\eta$ & $\eta_{\text {wfus }}$ & $\tan \alpha$ & $f_{k}$ \\
\hline 0.85 & 0.35 & 0.82 & 19.2 \\
\hline
\end{tabular}

Table 1: Values of parameters issued from automatic identification.

Using equations (6) and (7), an estimation of the droplets temperature can be done. Taking a fixed value $c_{p, w}=700 \mathrm{~J} \mathrm{~kg}^{-1} \mathrm{~K}^{-1}, \rho_{w}=7400 \mathrm{~kg} \mathrm{~m}^{-3}$ and $L_{w}=201897 \mathrm{~J} \mathrm{~kg}^{-1}$, we get: $T_{\text {drops } d}=2382^{\circ} \mathrm{C}$, which is in very good agreement with the average droplet temperature of $2400^{\circ} \mathrm{C}$ determined for mild steel by Jelmorini et al. (1977). This expresses the consistency of the identified solution.

Figure 9 shows the comparison between calculated and measured temperatures at the three characteristic thermocouple positions of the test: TC3 below the weld bead, TC2 and TC1 respectively 5 and $10 \mathrm{~mm}$ aside from the welding line. It can be seen that there is a good global agreement. However, significant differences can be observed during the rapid transient undergone when the electrode passes by the thermocouples. Calculated peak values are systematically higher than measured ones, and the difference increases with temperature. For instance, a rather good agreement is found for the peak temperature at $\mathrm{TC} 1$ : the measured peak value is $425^{\circ} \mathrm{C}$ whereas the calculated peak value is $460^{\circ} \mathrm{C}$. But the difference is higher at TC3: measured $680^{\circ} \mathrm{C}$, calculated $795^{\circ} \mathrm{C}$; and even higher at TC2: measured $660^{\circ} \mathrm{C}$, calculated $945^{\circ} \mathrm{C}$. From these results, two alternative and opposite statements may be expressed:

- A first statement would be that the global model is not capable - even after parameter optimization - of a good global representation of the different phenomena involved: heat and material supply, fusion and solidification, heat transfer. Several causes could be the source of this weakness: erroneous thermophysical properties, too simple Gaussian model for the surface heat source, wrong hypotheses governing the volume heat source, implementation and discretization errors...

- A second statement would be that the direct model fails only for peak values at TCs locations and that this would be due to erroneous recorded temperatures during such rapid transients. The reasons for that can be the size of thermocouples inducing offset times during measurements, the nature of the thermocouples itself creating heat contact resistances between welded wires and magnesia inside sensors, or a too loose contact between thermocouples and the base metal inducing heat contact resistances deep in the drilled holes.

What can help in deciding between those two statements is the quality of the prediction of the fusion zone, as this is part of the global objective function $\widetilde{\Psi}$. Figure 8 and Figure 10 show the difference between the observed and calculated transverse shape of the fusion zone. It can be seen that the characteristic shape is rather well represented. In particular the width, depth and volume of the fusion zone are in good agreement with the experiment. The shape of the finger part, especially its width variation vs depth shows some difference. This probably results from the fact that it has been chosen here not to optimize the volumetric source, but to determine it on the basis of literature results. It is likely that adding in the identification procedure one or two parameters describing this volumetric source, such as its radius, would lead to a better agreement. However, globally, the predicted characteristic dimensions of the weldment (width, depth, bead height) are quite close to those measured in the two transverse sections, as indicated in Table 2. 


\begin{tabular}{|c|c|c|c|}
\hline$[\mathrm{mm}]$ & width & height & depth \\
\hline Exp. Section S1 & 14.2 & 2.8 & 5.0 \\
\hline Exp. Section S2 & 13.5 & 2.9 & 5.2 \\
\hline Calc. & 13.4 & 2.7 & 5.2 \\
\hline
\end{tabular}

Table 2: Experimental average values of the characteristic dimensions of the fusion zone and predicted values after heat source parameters identification.

This expresses that the combination of the two heat sources, the Gaussian surface source and the cylindrical volume source, is probably a good representation of reality. In view of those results and considering that TCs positions are close enough to the fusion zone and that the thermophysical properties of $316 \mathrm{LN}$ are rather well known, our opinion is that between the two opposite statements expressed above, the second one can be validated: the disagreement for peak temperature values is the signature of wrong measurements for very high and fast transient temperatures. Hence the parameters of Table 1 can be validated and accepted as representative parameters for the studied GMA welding process when performed under such conditions. Finally, and as a last result, Figure 11 presents a view of the weld bead formation, as simulated by the present approach.

\section{Conclusion}

In this paper, original methods related to the modeling of material deposit and associated heat sources have been proposed for finite element simulation of GMAW in non-steady state conditions. The basic idea consists in implementing a source term in the mass conservation equation for some selected finite elements of the fusion zone. This approach permits the direct modeling of the formation of the weld bead, and thus offers an alternative to the element birth or element activation techniques that are commonly used to simulate the deposition of filler metal. By comparison with such usual methods, the new technique offers a significant advantage: the geometry of the joint does not need to be defined - and consequently meshed - prior to simulation. To be consistent with the above modeling of filler supply, the heat input is split in two contributions. A first contribution is a volume heat source corresponding to the energy transferred through the droplets of filler metal, for which a model taken from the literature is used. It should be noted that a specific expression of the corresponding source term in the energy equation is proposed here in coherency with the expression of mass supply. A second heat input contribution is a surface Gaussian heat source. Because several parameters of the global model have to be identified, an automatic parameter identification technique has been developed. It relies upon an inverse finite element method. The objective function to be minimized includes the differences between calculated and measured temperatures at different locations near the weld, but also penalty terms permitting a convenient and efficient comparison between the calculated and observed shapes of the fusion zone in the transverse section. Application has been shown on GMAW of steel $316 \mathrm{LN}$, for which the optimized set of parameters leads to a good agreement for temperatures and weld pool shape.

\section{Acknowledgement}

This study was supported by the companies Industeel (ArcelorMittal group) and Aubert et Duval. 


\section{References}

Aarbogh, H.M., Hamide, M., Fjaer, H.G., Mo, A. and Bellet, M. (2010), "Experimental validation of finite element codes for welding deformations", J. Mat. Proc. Tech., Vol. 210, pp. 1681-1689.

Bellet, M. and Fachinotti, V.D. (2004), "ALE method for solidification modelling", Comput. Meth. Appl. Mech. Eng., Vol. 193, pp. 4355-4381.

Bellet, M., Jaouen, O. and Poitrault, I. (2005), "An ALE-FEM approach to the thermomechanics of solidification processes with application to the prediction of pipe shrinkage", Int. J. Num. Methods Heat Fluid Flow, Vol. 15, pp. 120-142.

Cao, Z., Yang, Z. and Chen, X.L. (2004), "Three-dimensional simulation of transient GMA weld pool with free surface", Welding J., June (supplement), pp. 169S-176S.

Egorov, I.N., Kretinin, G.V., Leshchenko, I.A. and Kuptzov, S.V. (2005), "Optimization of complex technical systems", Proc. $9^{\text {th }}$ Int. Conf. on 'Computer Aided Optimum Design in Engineering', Skiathos, Greece, May 2005, Wessex Institute of Technology, pp. 335-340.

Goldak, J. (1986), "Computer modelling of heat flow in welds", Metall. Trans. B, Vol. 17, pp. 587-600.

Hamide, M. and Bellet, M. (2007), "Adaptive mesh technique for coupled problems. Application to welding simulation", Proc. $9^{\text {th }}$ Int. Conf. on Numerical Methods in Industrial Forming Processes, Porto, Portugal, American Institute of Physics, pp. 1561-1566.

Hamide, M., Massoni, E. and Bellet, M. (2008), "Adaptive mesh technique for thermal-metallurgical numerical simulation of arc welding processes", Int. J. Num. Meth. Engng., Vol. 73, pp. 624-641.

Hamide, M. (2008), "Modélisation numérique du soudage à l'arc des aciers", PhD thesis, MINES ParisTech, France.

Hu, J., Guo, H. and Tsai, H.L. (2008), "Weld pool dynamics and the formation of ripples in 3D gas metal arc welding", Int. J. Heat Mass Transfer, Vol. 51, pp. 2537-2552.

Jelmorini, G., Tichelaar, G.W. and van den Heuvel, G.J.P.M. (1977), "Droplet temperature measurements in arc welding", Report 212-411-77, Int. Institute of Welding (IIW), 22 pages.

Jones, L.A., Eagar, T.W. and Lang, J.H. (1998), "A dynamic model of drops detaching from a gas metal arc welding electrode", J. Phys. D: Appl. Phys., Vol. 31, pp. 107-123.

Kim, C.H., Zhang, W. and DebRoy, T. (2003), "Modeling of temperature field and solidified surface profile during gas-metal arc fillet welding", J. Appl. Phys., Vol. 94, pp. 2667-2679.

Kumar, S. and Bhaduri, S.C. (1994), "Three-dimensional finite element modeling of gas metal arc welding", Metall. Mater. Trans B, Vol. 25, pp. 435-441.

Kumar, A. and DebRoy, T. (2004), "Guaranteed fillet weld geometry from heat transfer model and multivariable optimization", Int. J. Heat Mass Transfer, Vol. 47, pp. 5793-5806.

Lancaster, J.F. (1986), The Physics of Welding, Pergamon Press, New York.

Lindgren, L.E., Runnemalm, H. and Näsström, M. (1999), "Simulation of multipass welding of a thick plate", Int. J. Num. Methods Eng., Vol. 44, pp. 1301-1316.

Lindgren, L.E. (2001), "Finite element modelling and simulation of welding. Part 1: Increased complexity; Part 2: Improved material modelling; Part 3: Efficiency and integration", J. Thermal Stresses, Vol. 24, pp. 141-192; 195$231 ; 305-334$.

Lindgren, L.E. (2006), "Numerical modelling of welding", Comp. Meth. Appl. Mech. Eng., Vol. 195, pp. 6710-6736. 
Pequet, C., Lasne, P., Hamide, M., Massoni, E. and Bellet, M. (2006), "A coupled approach for the modelling of arc welding processes", Proc. $11^{\text {th }}$ Int. Conf. on Modeling of Casting, Welding and Advanced Solidification Processes, Opio, Gandin, Ch.-A. and Bellet, M. (eds.), The Minerals, Metals \& Materials Society, pp. 855-862.

Rhee, S. and Kannatey-Asibu Jr., E. (1992), "Observation of metal transfer during gas metal arc welding", Weld. J., Vol. 71, pp. 381S-386S. 


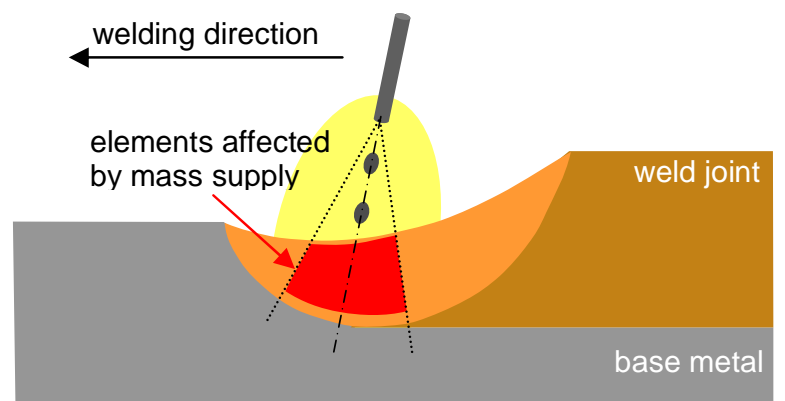

Figure 1: Schematic representation for the modeling of material deposit in GMA welding. 


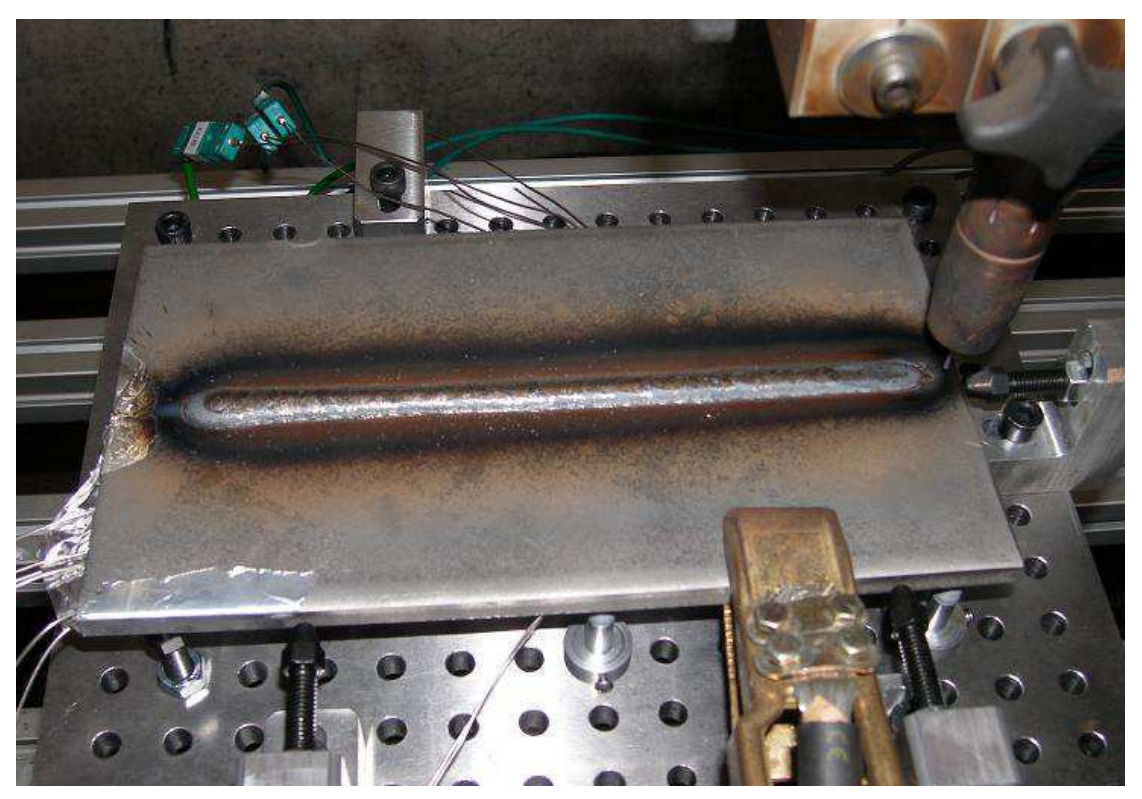

Figure 2: GMA welding experiment. 


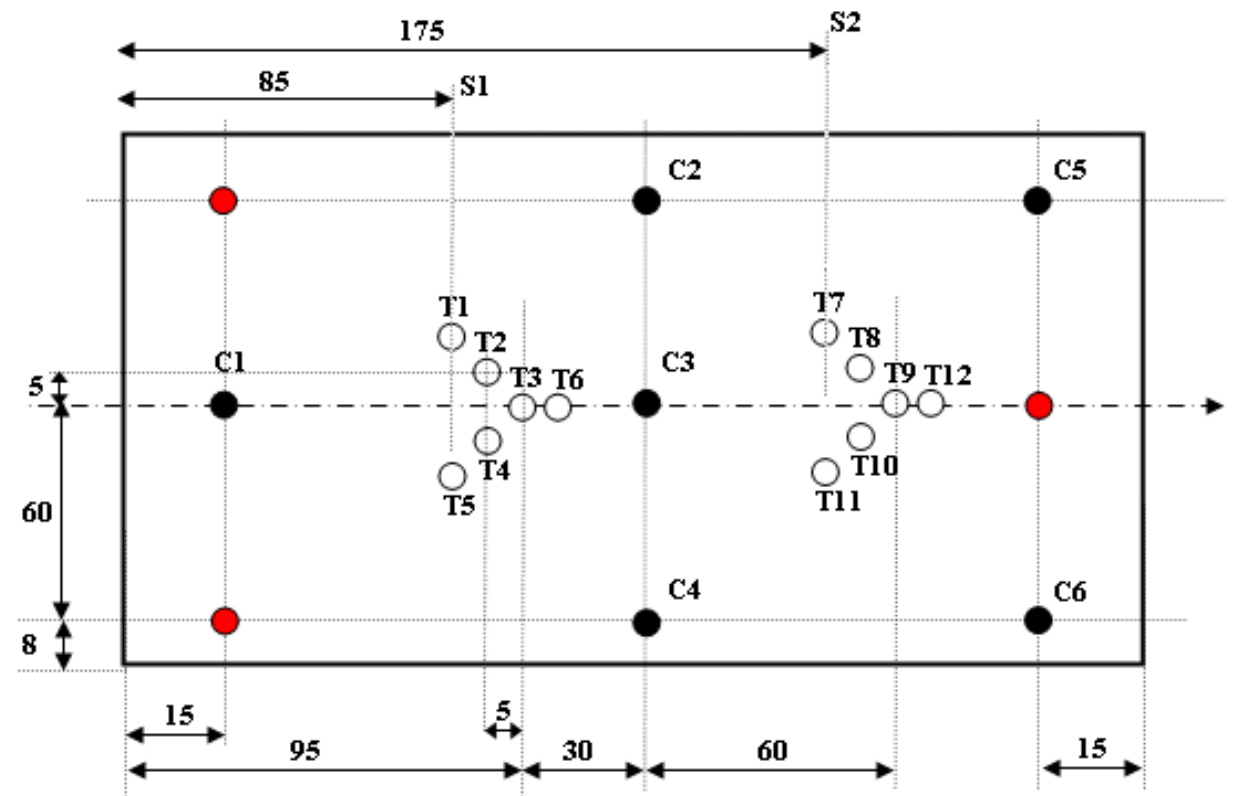

Figure 3: Instrumentation of the plate. White dots labelled "Tx" indicate the location of 12 thermocouples. Thermocouples below the weldment $(3,6,9,12)$ are located at $5.5 \mathrm{~mm}$ below the upper surface; others are located $3.5 \mathrm{~mm}$ below. Red dots not labelled indicate 3 supporting pins. Black dots labelled "Cx" indicate 6 LVDT sensors following the vertical displacement of the lower face of the plate (not used in this study). All dimensions in mm. 


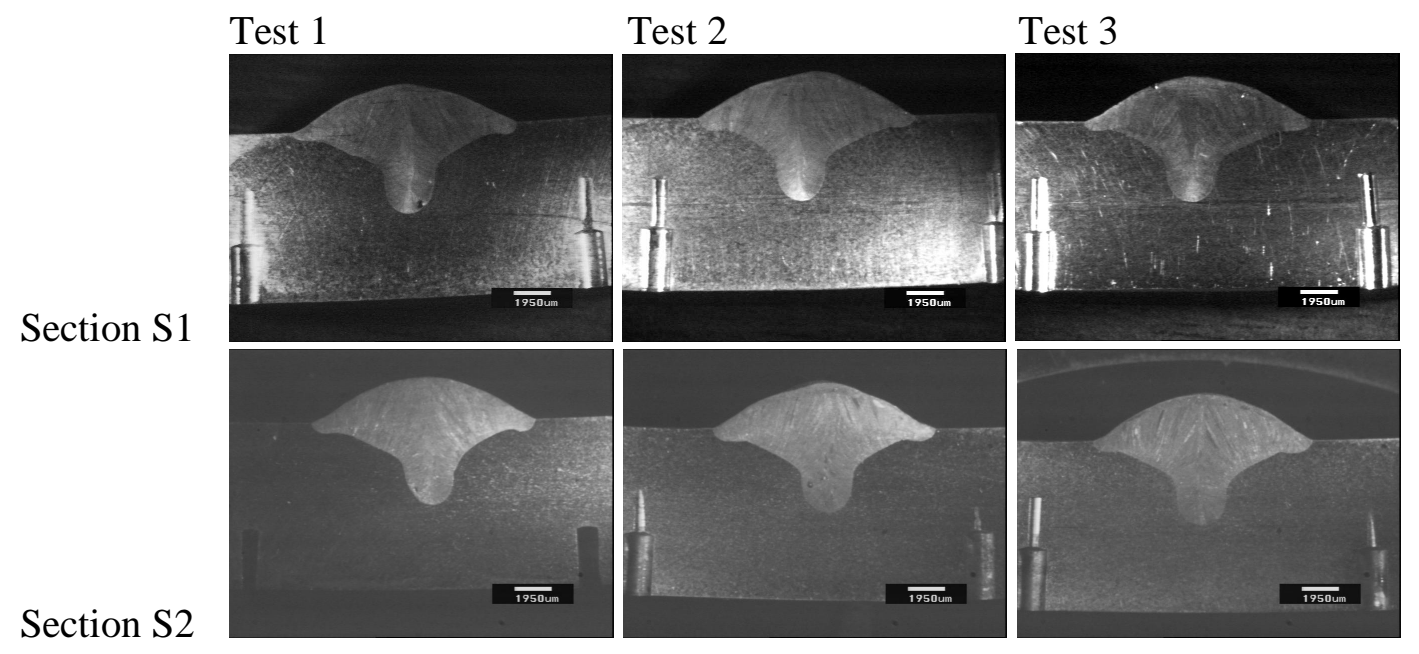

Figure 4: Macrographies showing the shape of fusion zones from three tests, along transverse sections S1 (top line) and S2 (bottom line) as indicated in Figure 3. Pre-drilled holes for the placement of thermocouples are visible. 


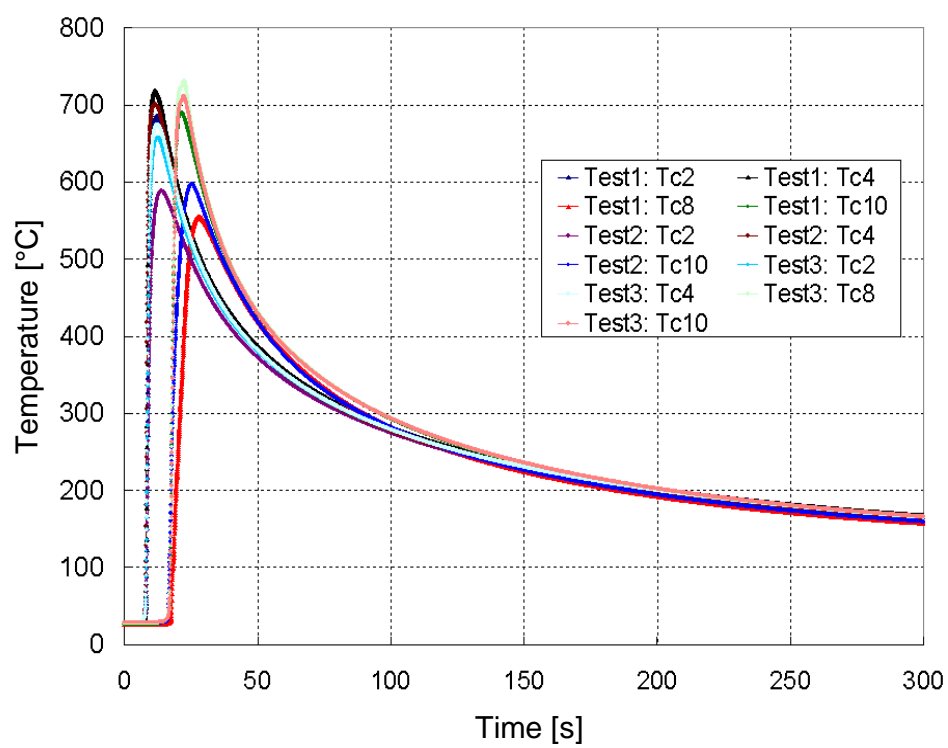

Figure 5: Temperature measurements at thermocouples 2, 4, 8 and 10 for three different tests. TCs 2 and 4 form a first peak at $9 \mathrm{~s}$, followed by a second peak for TCs 8 and 10 at $18 \mathrm{~s}$. 


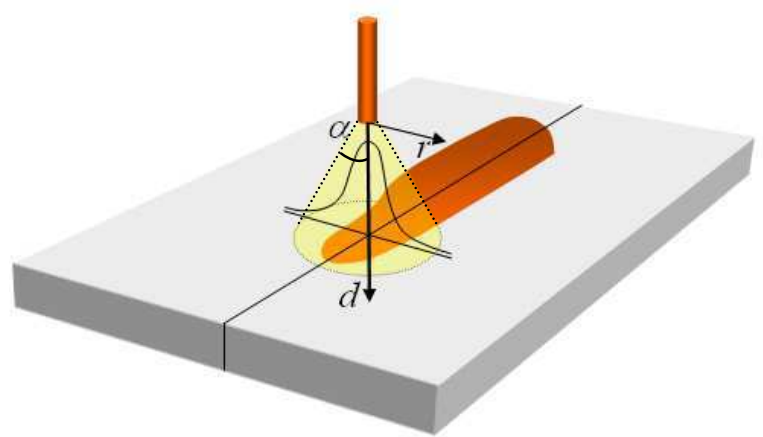

Figure 6: Schematic representation of the Gaussian distribution of the heat surface flux corresponding to the heat transfer from the arc to the plate. 


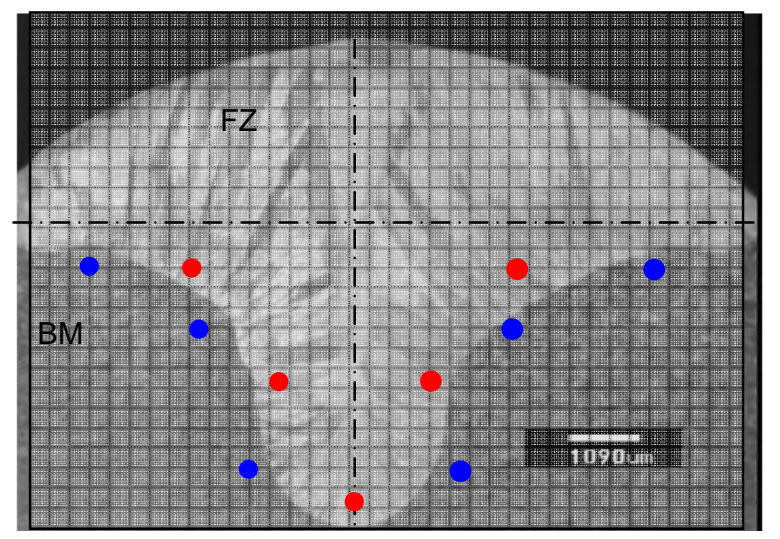

Figure 7: Principle of selection of locations in the fusion zone (FZ, marked by red dots) and in the base metal (BM, blue dots) in view of inverse analysis for heat source identification. 


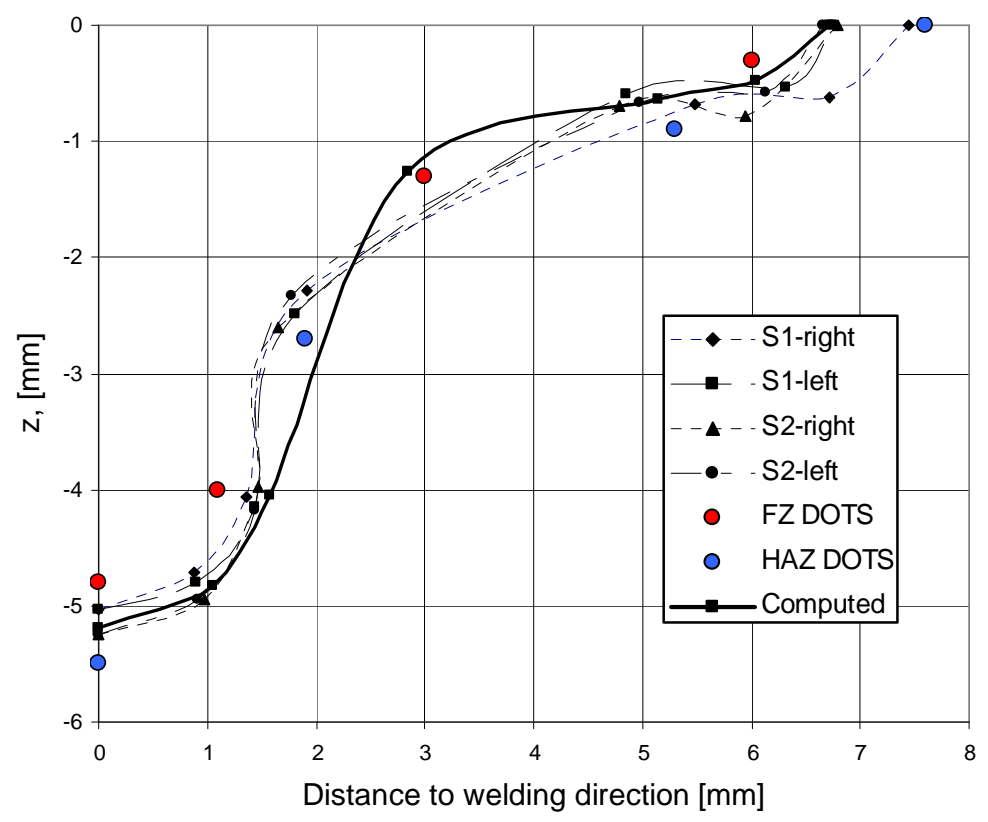

Figure 8: Profiles of the fusion zone, computed and as deduced from macrographies of test 3 shown in Figure 4. Right and left profiles of sections S1 and S2 are plotted. The horizontal coordinate represents the distance to the welding symmetry plane, as deduced from the macrographies. The vertical coordinate is the distance to the upper surface of the plate. The figure shows the location of red and blue dots in the fusion zone and the base metal, respectively. 


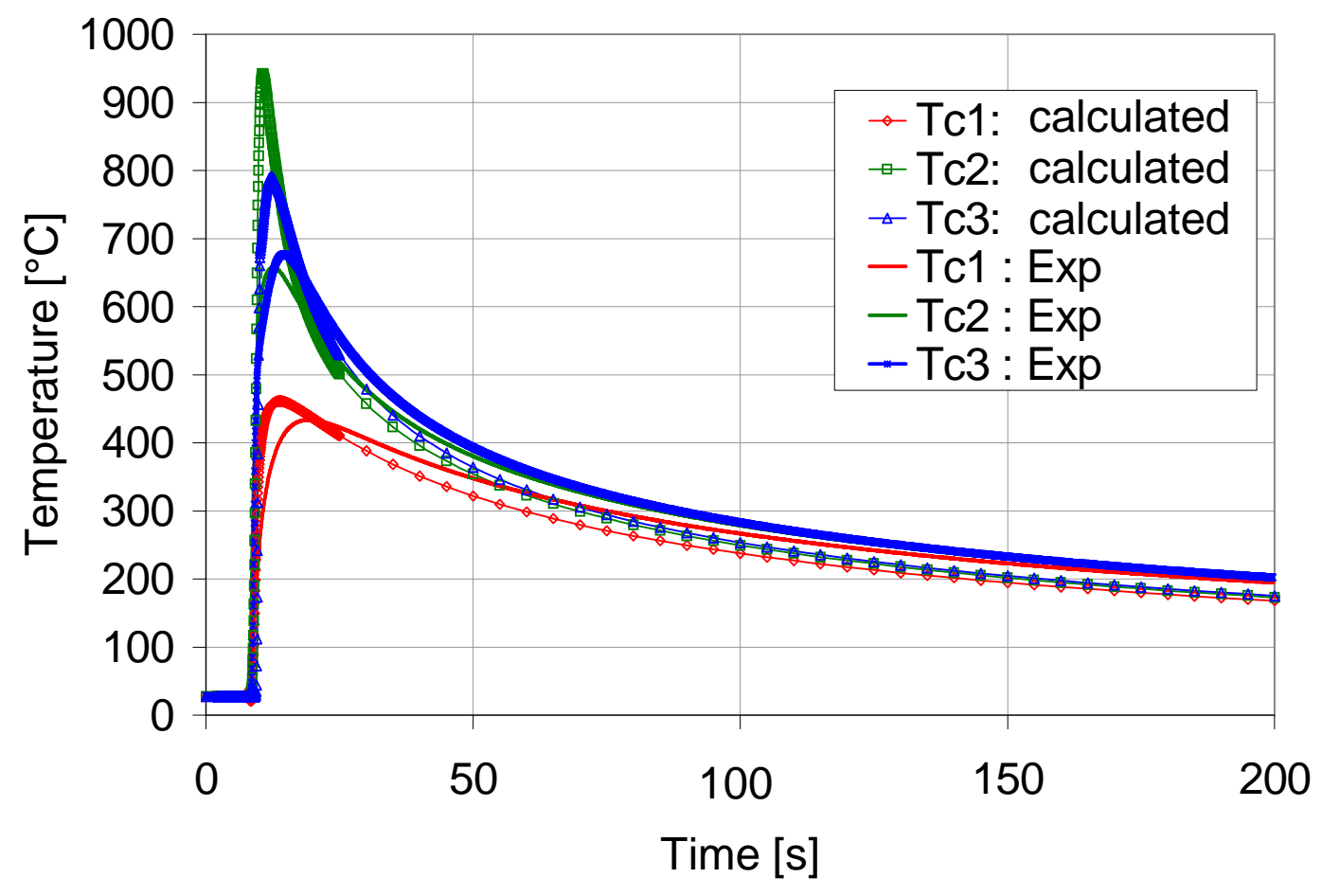

Figure 9: Experimental and numerical temperature evolution at different selected locations. 

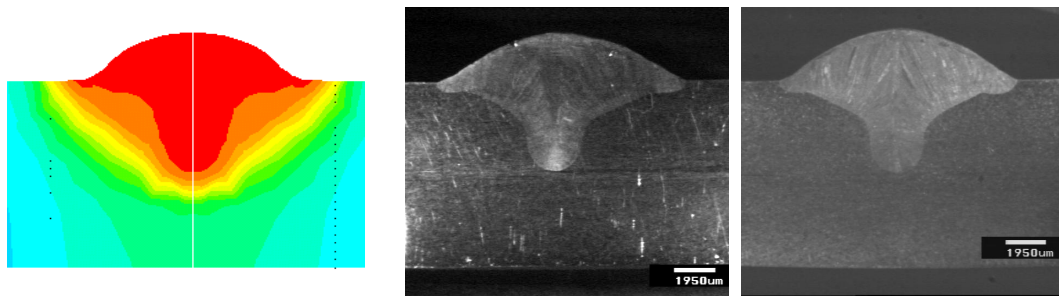

Section S1

Section S2

Figure 10: Calculated (on the left) and observed shapes of the fusion zone (on the right, transverse sections S1 and $\mathrm{S} 2$ of test 3). Red color indicates temperatures greater than the solidus temperature $\left(1420^{\circ} \mathrm{C}\right)$. 


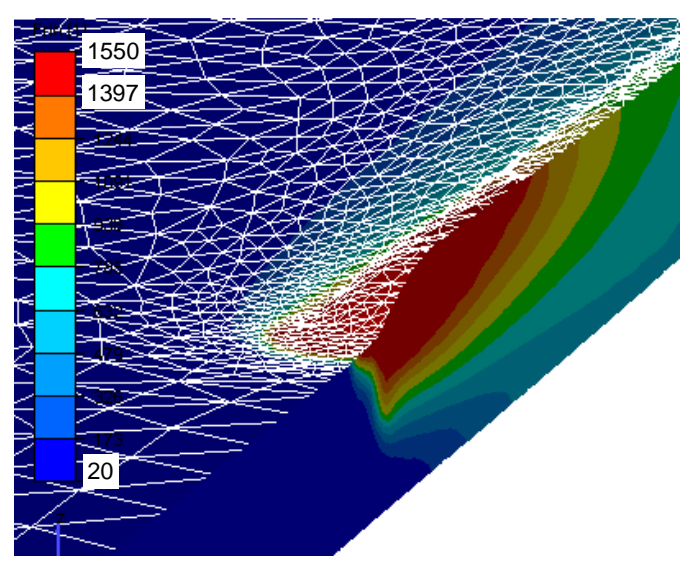

Figure 11: Temperature distribution and adapted finite element mesh. 